\title{
PRODUTIVISMO ACADÊMICO E SUAS CONSEQUÊNCIAS PARA A PRODUÇÃO CIENTÍFICA NA ÁREA DE ADMINISTRAÇÃ̃ ${ }^{1}$
}

\author{
Ely Severiano Junior ${ }^{2}$
}

Diego de Oliveira da Cunha ${ }^{3}$

Deborah Moraes Zouain ${ }^{4}$

Clayton Pereira Gonçalves ${ }^{5}$

http://dx.doi.org/10.1590/1413-2311.317.103796

\section{RESUMO}

O produtivismo acadêmico é uma prática que vem impactando de forma nociva a pesquisa científica ao longo dos últimos anos, sendo visto como uma anomalia, em que o pesquisador é praticamente obrigado - de forma normativa e institucional - a ter um determinado número de produção científica para se manter dentro dos programas de pós-graduação. O objetivo deste artigo é identificar como o grau de imersão em processos sociais de influência pode aumentar o produtivismo acadêmico em pesquisadores da área de Administração. A pesquisa tem natureza qualitativa e quantitativa, pois, durante sua realização, foram extraídos dados da Plataforma Lattes e também dados oriundos de entrevistas com pesquisadores que fazem parte dos programas de pós-graduação que possuem nota de 5 a 7 na avaliação CAPES. Observou-se que os programas que possuem alta produção de artigos influenciam os seus pesquisadores a terem uma produção compatível com a do programa. Os resultados da pesquisa confirmam a ideia proposta pela teoria da influência social, pois os pesquisadores estão interessados em publicar somente como primeiros autores, sendo essa autoria dada através da consolidação da rede com os mesmos coautores e, muitas das vezes, de forma indevida. Por fim, recomenda-se que para futuras pesquisas seja analisado como a influência social é exercida sobre os orientandos.

\footnotetext{
${ }^{1}$ Recebido em 1/6/2020, aceito em 6/5/2021.

${ }^{2}$ Instituto Federal de Educação, Ciência e Tecnologia do Rio de Janeiro - Eng. Paulo de Frontin - RJ (Brasil); https://orcid.org/0000-0001-5930-8251; ely.severiano@ifrj.edu.br.

3 Centro Federal de Educação Tecnológica Celso Suckow da Fonseca - Programa de Pós-Graduação em Engenharia de Produção e Sistemas; Rio de Janeiro - RJ (Brasil); https://orcid.org/0000-0002-0738-046X; diego.cunha@aluno.cefet-rj.br.

${ }^{4}$ Universidade do Grande Rio - Programa de Pós-Graduação em Administração; Duque de Caxias - RJ (Brasil); https://orcid.org/0000-0003-4813-9741; deborah.zouain@unigranrio.edu.br.

5 Fundação Universidade Federal de Rondônia - Departamento Acadêmico de Administração; Vilhena - RO (Brasil); https://orcid.org/0000-0001-9743-8057; clayton.goncalves@ unir.br.
} 
Palavras-chave: Produtivismo Acadêmico. Trabalho docente. Educação Superior.

\section{ACADEMIC PRODUCTIVITY AND ITS CONSEQUENCES FOR SCIENTIFIC PRODUCTION IN ADMINISTRATION}

Academic productivism is a practice that has had a harmful impact on scientific research over the past few years, being seen as an anomaly, where the researcher is practically obliged - in a normative and institutional manner - to have a certain number of scientific outputs to remain within graduate programs. The objective of this article is to identify how the degree of immersion in social processes of influence can increase academic productivism in Management researchers. The research has a qualitative and quantitative nature, because during the research data were extracted from the Lattes platform, and also data through interviews with researchers who are part of the graduate programs that have grades 5 to 7 in the CAPES assessment., It was observed that the programs that have a high production of articles influence their researchers to have a production compatible with that of the program. The results of the research confirm the idea proposed by the theory of social influence, as researchers are interested in publishing only as first authors, this authorship being given through the consolidation of the network with the same co-authors, and many times, in an improper way. Finally, it is recommended that for future research it is analyzed how the social influence exerted on the students.

Keywords: Academic Productivism. Teaching work. College education.

\section{EL PRODUCTIVISMO ACADÉMICO Y SUS CONSECUENCIAS PARA LA PRODUCCIÓN CIENTÍFICA EN LA ADMINISTRACIÓN}

El productivismo académico es una práctica que viene impactando de manera nociva la investigación científica en los últimos años, siendo vista como una anomalía, donde el investigador está prácticamente obligado - de forma normativa e institucional - a tener un determinado número de producción científica para poder mantenerse dentro de los programas de posgrado. El objetivo de este artículo es identificar cómo el grado de inmersión en procesos sociales de influencia puede incrementar la productividad académica en los investigadores de Gestión. La investigación tiene un carácter cualitativo y cuantitativo, pues durante la investigación se extrajeron datos de la Plataforma Lattes, y también datos a través de entrevistas con investigadores que forman parte de los programas de posgrado que tienen grados 5 a 7 en la evaluación CAPES. Se observó que los programas que tienen una alta producción de artículos influyen en sus investigadores para que tengan una producción compatible con la del programa. Los resultados de la investigación confirman la idea propuesta por la teoría de la influencia social, ya que a los investigadores les interesa publicar solo como primeros autores, dando esta autoría a través de la consolidación de la red con los mismos coautores, y la mayoría de las veces de forma indebida. Finalmente, se recomienda que para futuras investigaciones se analice cómo la influencia social que se ejerce sobre los orientandos.

Palabras clave: Productividad académica. Trabajo de enseñanza. Educación universitária. 


\section{INTRODUÇÃO}

O produtivismo acadêmico se refere a uma produção de material científico realizada em grande quantidade, visando ao princípio mercadológico de se manter bem posicionado dentro do segmento no qual o pesquisador está envolvido (RICCI, 2009). Contudo, para Torrisi (2013), o produtivismo acadêmico é uma combinação de resultados gerados pelo desempenho científico, um produto ou serviço (patente) e ensino. Nesse sentido, observa-se que Torrisi (2013) e Ricci (2009) não estão em desacordo, uma vez que as suas definições para produtivismo acadêmico são complementares. Sendo assim, esse fator se deve a uma disputa interna por um maior número de publicações em periódicos com o maior fator de impacto (ALVESSON, 2013).

Desse modo, com esta pesquisa, pretende-se analisar como o nível de imersão em processos sociais de influência pode aumentar o produtivismo acadêmico em pesquisadores da área de Administração. Esse nível de imersão é mensurado a partir das seguintes dimensões: (i) Relação entre pesquisador e programa ao qual ele está associado; (ii) Relação entre pesquisador e rede de coautoria; (iii) Relação entre período produtivista e pesquisador.

Em pesquisas anteriores, constatou-se que a estrutura de rede de colaboração mexicana em pesquisa científica tem se tornando um elemento essencial no aumento de produtividade acadêmica (GONZALEZ-BRAMBILA et al., 2013). Além disso, também foi feito um estudo multidisciplinar para identificar se a performance de grupo de pesquisadores italianos de uma determinada área influía na performance individual de cada pesquisador inserido naquela mesma área de atuação (ABRAMO et al., 2011). Nesses dois estudos, foi constatado que as estruturas de redes sociais têm se tornado um elemento vital para compreender o perfil da produção científica de qualquer área de conhecimento.

Para trazer esse contexto para o cenário brasileiro, foi feito um levantamento anterior, por meio da Plataforma Lattes, visando entender o perfil dos acadêmicos e das suas publicações, tendo como escopo o ano de 2014. Nesse estudo, foi descoberto que pesquisadores que estão em cidades como Rio de Janeiro e São Paulo possuem o maior número de produção de materiais científicos na área de administração (IMASATO et al., 2017). Além dessa, outra pesquisa foi realizada com o objetivo de entender a estrutura de rede de coautoria, que era entendida como uma rede informal, e o relacionamento entre o pesquisador e o programa de pós-graduação, compreendido como uma rede formal. Observa-se, nesta última, que houve um aumento na rede de coautoria entre os triênios 2001-2003 para 2004-2006 nos programas de pós-graduação em Administração (MARQUES DE MELLO et al., 2009). 
A publicação de um artigo é essencial para a vida de um professor pesquisador, pois inclui algumas recompensas materiais, tais como promoção, aumento de autoestima, aumento de status e é uma condição para manter o emprego em uma boa universidade (REGO, 2014). Por essa lógica, houve um grande aumento da competitividade nos programas de pósgraduação.

Buscando alavancar o número de produções de artigos feitos em um determinado período, ainda existe um outro fenômeno alavancador de produções científicas que é a coautoria (GONZALEZ-BRAMBILA et al., 2013). Conhecido por criar mecanismos de parceria entre vários autores, cria-se uma rede de colaboração multinível que acaba representada por diversos modos, tais como parcerias institucionais, interprogramas e internacionais (DUCTOR, 2015; INKPEN et al., 2005; PHELPS et al., 2012). Todas elas visam facilitar a transferência do conhecimento em rede (PHELPS et al., 2012).

Apesar de estudos anteriores demonstrarem o estado da arte da prática do produtivismo acadêmico em pesquisadores da área de Administração no Brasil (IMASATO et al., 2017; MARQUES DE MELLO et al., 2009), não se identificou nenhum estudo atual que tivesse, em seu escopo, uma extração atualizada da Plataforma Lattes que utilizasse como plano de fundo a teoria da influência social, com o objetivo de explicar o grau de imersão de um determinado pesquisador na prática do produtivismo acadêmico. A partir disso, o presente artigo pretende analisar como o nível de imersão em processos sociais de influência pode aumentar o produtivismo acadêmico em pesquisadores da área de Administração em programas localizados nos estados do Rio de Janeiro, São Paulo e Rio Grande do Sul que possuam nota igual ou superior a cinco na última avaliação da Coordenação de Aperfeiçoamento de Pessoal de Nível Superior (CAPES), sendo analisadas as publicações realizadas no período de 2013 a 2018.

\section{PRODUTIVISMO ACADÊMICO}

Quando um pesquisador realiza uma determinada pesquisa, muitas vezes, ele não pensa na inovação que a pesquisa pode trazer para aquela área. Para Kuhn e Epstein (1979), o trabalho dentro de um assunto consolidado e profundamente difundido está mais próximo de um impacto maior do que um trabalho que traz um viés inovador, pois esse trabalho não possui similares publicados. Nesse contexto, conforme Foster (2015), para se manter dentro do campo de pesquisa, é necessário ter produtividade e, para isso, os cientistas fazem contribuições incrementais para assuntos de pesquisas já consolidados. 
O produtivismo acadêmico diz respeito a um assunto complexo; para entender melhor o seu funcionamento, faz-se necessário dividi-lo em quatro partes, sendo elas: (i) produtividade científica do primeiro tipo, que é correspondente às publicações científicas; (ii) produtividade científica de segundo tipo, que é correspondente ao recebimento de prêmios e conquista de status acadêmico; (iii) produtividade em termos de relações externas (ou aconselhamento externo); (iv) produtividade didática ou educacional (TORRISI, 2013).

Dentre esses quatro tipos de produtivismo, o mais valorizado pela academia é a produção de primeiro tipo, pois, nesse produtivismo, é valorizada a quantidade de material científico produzido por um determinado autor. Assim, o número de artefatos científicos produzido em um determinado período define, também, como serão geridos os recursos para bolsas em programas de pós-graduação e investimentos para financiar as pesquisas realizadas. Nesse sentido, essa pressão externa e interna por produtivismo atinge tanto docentes/pesquisadores, quanto discentes de programas de pós-graduação (REGO, 2014).

Além disso, segundo Bosi (2007), os editais disponibilizados pelos órgãos de fomento de pesquisa, como o Conselho Nacional de Desenvolvimento Científico e Tecnológico (CNPq) e a CAPES, avaliam o pesquisador pelo número de produções que ele fez durante um determinado período. Esse aumento se deve por $90 \%$ da avaliação quadrienal que é feita nos programas de pós-graduação em Administração e considera a produção intelectual realizada por docentes, discentes e egressos em base indexada no Qualis CAPES, seja essa avaliação feita de forma qualitativa, seja de forma quantitativa (CAPES, 2016).

A mudança, talvez, mais impactante na mensuração de qualidade de programas de pósgraduação foi a feita pela CAPES a partir do biênio 1996/1997, pois o foco da avaliação passou a ser voltado para formação dos pesquisadores, e não mais a partir da formação dos professores, como era praticada anteriormente (SGUISSARDI, 2010). Essa mudança impulsionou a lógica produtivista, na qual o indivíduo demonstra a "qualidade" de seus trabalhos por meio dos números, de modo totalmente quantitativo.

Segundo Bianchetti e Valle (2014, p. 97):

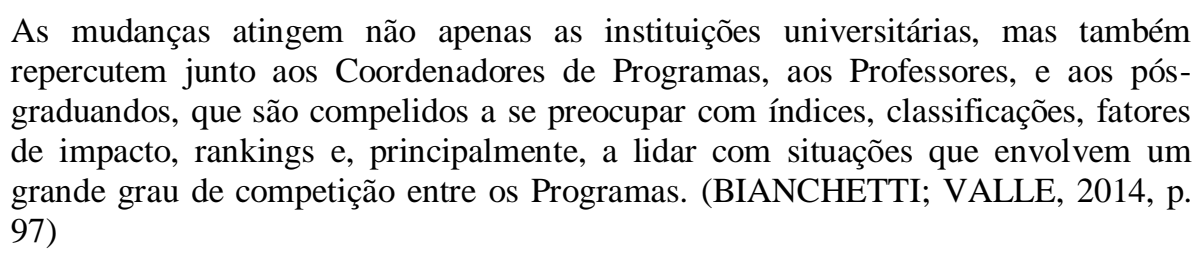

Para Gatti et al. (2003), o modelo atual está baseado fundamentalmente na avaliação externa e centrada em produtos. Pode-se notar que o método de avaliação utilizado pela CAPES (c) (1) $(9)$ 
preza unilateralmente pela produção científica que é exercida pelos programas de pósgraduação, por ter o objetivo de padronizar todos os programas e levá-los a uma cultura altamente produtivista. Desse modo, é difundida uma cultura produtivista que perpassa o docente, o discente e o programa.

O que contraria o objetivo de criação da pós-graduação brasileira, uma vez que o seu objetivo era formar professores que atendiam a qualidade da expansão do ensino superior e preparar o caminho para o decorrente desenvolvimento da pesquisa científica (GATTI et al., 2003). A pós-graduação foi instituída no Brasil como modalidade e ensino formal por meio do Parecer CFE no 977/1965, com o objetivo de qualificar o corpo docente das universidades brasileiras de modo parecido com que era praticado em universidades americanas e germânicas (BRASIL, 1965).

Nos últimos anos, aconteceu um aumento exponencial de programas de pós-graduação no Brasil; consequentemente, houve também o aumento da produção intelectual (SHIGAKI; PATRUS, 2013). Desse modo, o Brasil se tornou o país com o maior volume de produção intelectual da América Latina, observando alguns aspectos, tais como o número de artigos produzidos, número de citações, número de autocitação e índice h. O número é tão expressivo no que tange ao número de produções que a diferença em relação ao segundo colocado é muito alta, pois o número brasileiro é equivalente a, aproximadamente, três vezes mais (como podemos observar na Figura 1).

Figura 1 - Ranking de produção científica da América Latina (1996-2018)

\begin{tabular}{|c|c|c|c|c|c|c|c|}
\hline Rank & Country & Documents & Citable documents & Citations & Self-citations & Citations per document & H index \\
\hline & 1 Brazil & 938352 & 888530 & 10225275 & 3363421 & 10,9 & 530 \\
\hline & 2 Mexico & 318095 & 298719 & 3760403 & 737110 & 11,82 & 411 \\
\hline & 3 Argentina & 209294 & 196041 & 3059605 & 596324 & 14,62 & 393 \\
\hline & 4 Chile & 147389 & 139063 & 2082880 & 389445 & 14,13 & 349 \\
\hline & 5 Colombia & 99301 & 93376 & 947241 & 145857 & 9,54 & 261 \\
\hline & 6 Venezuela & 40072 & 38214 & 475567 & 52758 & 11,87 & 205 \\
\hline & 7 Cuba & 39570 & 37602 & 316847 & 56281 & 8,01 & 166 \\
\hline & 8 Peru & 25175 & 22751 & 370379 & 39297 & 14,71 & 212 \\
\hline & 9 Uruguay & 19229 & 17929 & 319563 & 38309 & 16,62 & 179 \\
\hline & 10 Ecuador & 18795 & 17681 & 193326 & 25436 & 10,29 & 149. \\
\hline
\end{tabular}

Fonte: Scimago (2018).

Visando entender como se dá a produção intelectual no Brasil, iremos elencar, a seguir, como é feita a avaliação realizada pela CAPES nos programas de pós-graduação que estão dentro da área de Administração no Brasil, uma vez que a produção intelectual nessa área se dá, principalmente, pelo empenho de professores, discentes e egressos dos programas de pósgraduação. É importante ressaltar que cada área possui uma ficha de avaliação específica. Para 
essa análise, foi utilizada a ficha destinada apenas para a área de administração, compreendendo as subáreas: administração, contabilidade e turismo. Dentro do quadriênio 2013-2016, segundo a CAPES (2016), os quesitos para avaliação dos programas de mestrado e doutorado acadêmico na área de Administração foram: (i) Proposta do Programa (não tendo percentual estipulado); (ii) Corpo Docente (equivalente a 20\%); (iii) Corpo Discente, Teses e Dissertações (equivalente a 35\%), (iv) Produção Intelectual (equivalente a 35\%) (v) Inserção Social (equivalente a 10\%). Observa-se que praticamente $70 \%$ da nota, na avaliação, gira em torno da produção intelectual, seja essa produção feita pelo corpo docente, pelo corpo discente ou pelos egressos do programa (CAPES, 2016).

\section{REDES COMO MECANISMO DE INFLUÊNCIA}

A influência social explica o motivo da alteração ou adaptação do comportamento de determinados indivíduos, pois os indivíduos tendem a alterar os seus comportamentos de acordo com o comportamento dos indivíduos com os quais eles se relacionam ou interagem (FRIEDKIN, 1998). Desse modo, um determinado indivíduo costuma explicitar um comportamento semelhante ao de um outro com quem ele se relaciona em seu cotidiano. Nesse sentido, indivíduos que possuem características estruturalmente equivalentes tendem a ter uma postura muito mais homogênea. Portanto, possuem cognição e comportamentos semelhantes em relação a outras pessoas que possuem papéis centrais (FRIEDKIN, 1984). Logo, a congruência em conhecimentos e opiniões ajuda na transferência de conhecimentos, visto que os atores tendem a achar mais fácil absorver novas ideias de áreas que, de algum modo, já possuem algum conhecimento prévio, do que de áreas em que teriam que iniciar uma compreensão sobre um determinado tema (REAGANS; MCEVILY, 2003). Esse processo, consequentemente, desencadeia uma alteração de comportamento de um determinado indivíduo, seja essa alteração de forma intencional, seja de forma arbitrária, como resultado da ação de um determinado sujeito denominado como influenciador (FRIEDKIN, 1998).

Em contraponto, atores que são estruturalmente menos congruentes tendem a ter diferentes norteadores de conhecimento, o que, consequentemente, torna o conhecimento mais caro, portanto, dedicam mais tempo e esforço para sua obtenção, o que faz com que ele seja mais intangível (REAGANS; MCEVILY, 2003).

Para demonstrar como a teoria da influência social se manifesta, Friedkin (1998) criou um quadro teórico para influência social como um processo que acontece em rede; Strang e Friedkin (2000) analisaram essa abordagem e reforçaram a análise da coesão na análise de rede. 
Nesse contexto, para ter produtividade, os pesquisadores precisam estabelecer relacionamentos. Desse modo, Foster (2015) desenvolveu cinco estratégias que um novo pesquisador pode utilizar para conseguir obter uma rede de relações científicas conhecidas. A estrutura é baseada em uma lógica de combinação molecular. Essa rede é dada por um ciclo contínuo com as seguintes etapas: salto, nova consolidação, nova ponte, consolidação repetida e ponte repetida (FOSTER, 2015). Dessa maneira, a estrutura da rede de relacionamento científico denota um elemento importante no que tange à produção de artefato científico, pois o pesquisador precisa estar inserido nessa rede de relacionamento de maneira contínua para ter condições mínimas de provocar algum impacto em suas produções científicas. Essa representação ajuda a entender, por meio de uma visão macro, a rede de coautorias entre grupos de pesquisadores (FOSTER, 2015).

O novo pesquisador precisa ser incluído em um grupo de pesquisa, sendo esse grupo denominado como cluster A, devido sua estrutura. Desse modo, ele entra em um ciclo contínuo percorrendo algumas etapas, conforme abaixo:

i. Sendo a primeira etapa, o primeiro salto que ele vai precisar fazer para ingressar nesse cluster, seja esse salto manifestado por meio de uma parceria ou, até mesmo, o ingresso desse novo pesquisador em um programa de pós-graduação como discente, como docente, como orientando de programa de pós-doutorado ou como professor visitante (GONZALEZ-BRAMBILA et al., 2013);

ii. Posteriormente, ele vai precisar dar um novo salto na busca de se consolidar nesse cluster. Para isso, esse novo pesquisador precisa começar a publicar em periódicos que tenham um Qualis CAPES alto, ou até mesmo um alto fator de impacto (GULATI, 1995). Nessa etapa, o novo pesquisador pode dar mais um salto buscando se consolidar cada vez mais dentro desse cluster, ou seja, buscando publicar várias vezes nesses periódicos ou participar de congressos ou conferências com os principais speakers de sua área (INKPEN et al., 2005);

iii. Logo após essa consolidação dentro do cluster A, o autor precisa estabelecer um vínculo com um outro cluster, o cluster $\mathrm{B}$; sendo assim, ele precisa estabelecer uma ponte entre o cluster A e o cluster B (GONZALEZ-BRAMBILA et al., 2013). Essa ponte é manifestada por meio de uma parceria entre programas de pós-graduação da mesma área, sendo, preferencialmente, programas que já estejam consolidados nacionalmente ou internacionalmente. Nessa etapa, o pesquisador já se encontra totalmente consolidado dentro do cluster A (HE et 
al., 2009). Contudo, para estabelecer o vínculo com outro cluster, ele precisa trabalhar em uma temática de pesquisa que seja construída também dentro do cluster B, para assim estabelecer uma ponte (HE et al., 2009; TORRISI, 2013);

iv. Essa ponte pode ocorrer por meio de um vínculo interinstitucional, ou pode ser dada somente por meio da parceria de pessoa física entre os pesquisadores que fazem parte do cluster A e do cluster B (HE et al., 2009);

v. Em seguida, essa ponte criada entre os clusters A e B pode ser repetida várias vezes ou trabalhada de maneiras diferentes, seja por meio de um edital de fomento que exija a parceria entre, no mínimo, duas instituições distintas, ou mesmo entre dois pesquisadores associados a programas distintos ou, ainda, por uma parceria intersetorial, feita por meio de pesquisadores de diferentes estados ou de diferentes países (GONZALEZ-BRAMBILA et al., 2013; HE et al., 2009).

Desse modo, utilizaremos a Análise de Redes Sociais (ARS) para explicitar a alteração de comportamento desse indivíduo, pois, de acordo com Friedkin (2003), a teoria de influência social é uma rede social que se mantém estável e cuja principal função é a demonstração do seu reflexo no desencadeamento na mudança de atitude de um determinado indivíduo, sendo esse ato gerado a partir de uma pressão normativa. Nesse contexto, uma rede social de uma organização possui como principal característica a interconexão de diversos indivíduos que interagem e compartilham informação e conhecimento. Nem sempre a rede social organizacional estará associada a somente uma organização formal. Além disso, ela pode incluir relacionamentos intraorganizacionais (SOUZA; QUANDT, 2008).

\section{ANÁLISE DE REDES SOCIAIS}

A análise de redes sociais, também conhecida como Social Network Analysis (SNA), possui em sua composição elementos de suma importância para a sua estrutura (WASSERMAN; FAUST, 1994). A presença desses elementos ajudará na escolha de qual tipo de análise de rede será utilizada para compreender como as relações são feitas entre um determinado número de atores.

A análise de redes sociais ressalta a importância dos relacionamentos, medindo as relações formais e informais, com o objetivo de ajudar na compreensão das barreiras e dos elementos que facilitam a conexão dos fluxos de conhecimento com as unidades de interação. 
Portanto, trata-se de um método que está em crescente ascensão nas áreas de Ciências Sociais Aplicadas, Psicologia e Saúde (SERRAT, 2017). Desse modo, a análise de redes sociais é conhecida como um mecanismo que utiliza matemática - dentro da Sociologia -, visando estudar o comportamento humano de forma quantitativa (SOUZA; QUANDT, 2008).

Para Serrat (2017), os resultados de uma análise de redes sociais podem ser utilizados para: (i) identificar indivíduos, equipes que possuem papéis centrais em uma construção de conhecimento; (ii) impulsionar os fluxos de conhecimentos, criando oportunidades nos limites funcionais e organizacionais; (iii) identificar gargalos, buracos estruturais, equipes, indivíduos isolados e unidades.

A imersão ou "embeddedness" é um estudo que é iniciado com o Karl Polanyi, em 1944, por meio da obra The great transformation, com objetivo de explicar como organizações, grupos ou indivíduos que estão inseridos em um mesmo contexto podem se aproximar ou se distanciar (POLANYI et al., 1944). Desse modo, para Moody e White (2003, p. 105, tradução nossa):

\footnotetext{
'imersão' é um construto multidimensional que se relaciona geralmente com a importância das redes sociais para a ação. O nível de imersão indica que os atores que estão integrados em clusters densos ou relações multiplexadas de redes sociais enfrentam diferentes conjuntos de recursos e restrições do que aqueles que não estão embutidos nessas redes. ${ }^{6}$ (MOODY; WHITE, 2003, p. 105, tradução nossa)
}

A estrutura de uma imersão geralmente é estruturada em dois pilares, sendo o primeiro composto por pares de atores (díades) e o segundo pela estrutura das relações da rede. Sendo assim, Granovetter (1992) descreve que a estrutura da imersão é dada pelo nível que os atores estão envolvidos em grupos de coesão social. A coesão social pode ser definida, inicialmente, como o modo que impulsiona os indivíduos de um grupo a se manterem em um determinado grupo que interage a partir de um mesmo pressuposto (HEWSTONE, 2015; O'REILLY; ROBERTS, 1977). Dessa forma, todos os indivíduos que estão situados nesse determinado grupo tendem a ser estruturalmente coesos, mesmo tendo em vista que possam perpassar múltiplos caminhos relacionais entre todos os membros daquele determinado grupo (MOODY; WHITE, 2003).

\footnotetext{
${ }^{6}$ No original: “"embeddedness' is a multidimensional construct relating generally to the importance of social networks for action. Embeddedness indicates that actors who are integrated in dense clusters or multiplex relations of social networks face different sets of resources and constraints than those who are not embedded in such networks. By specifying an exact structural indicator for one dimension of social embeddedness, we move beyond orienting statements and augment our ability to develop cumulative scientific insights".
} 
Trazendo o contexto de imersão para a colaboração na produtividade acadêmica, percebe-se que quanto maior a densidade da rede, maior será a robustez na criação de novos conhecimentos, pois a densidade aumenta a confiança entre os participantes de uma determinada rede, desencadeando no compartilhamento de novos conhecimentos (FLEMING et al., 2007). A densidade é medida pela razão do número de laços reais pelo número de laços possíveis contidos em uma rede social (SCOTT, 2000).

\section{DESENVOLVIMENTO DE HIPÓTESES}

As estruturas sociais abertas com diversos buracos estruturais podem atrair a conexão de novos membros, trazendo-os para diversos clusters, conseguindo acesso a novas informações, aumentando o desempenho daquele determinado ator (PHELPS et al., 2012). Além disso, atores que estão em uma imersão mais densa conseguem obter um maior nível de confiança em outros atores que compõem essas redes, levando esses indivíduos a terem um alto desempenho (COLEMAN, 1988).

Assim, pesquisadores que possuem maior tempo de experiência tendem a fazer parte de redes mais colaborativas, proporcionando vantagem aos pesquisadores mais experientes na formação de laços de rede, e ajudando os novos pesquisadores a obterem acesso a novos laços de conexão (BURT, 2017; ZUCKERMAN, 1967). A produção intelectual realizada por um programa de pós-graduação é fundamental para a sua sobrevivência. Nesse sentido, segundo Imasato (2017), a avaliação dos programas de pós-graduação em administração valoriza a quantidade de publicações realizadas em um determinado período, de acordo com o sistema Qualis CAPES. Alguns editais de fomento de pesquisa exigem que o programa de pósgraduação no qual o pesquisador tenha vínculo esteja com nota mínima 5 na última avaliação quadrienal da CAPES. Sendo assim, o pesquisador associado a esse programa precisa ter um número razoável de produção acadêmica para concorrer a esses editais (PATRUS et al., 2015).

Os programas de pós-graduação dependem da nota que recebem da CAPES para se manter funcionando; os pesquisadores que estão associados a esses programas precisam se manter com um alto volume de produção científica para manter ou aumentar a nota que o programa recebe da avaliação da CAPES (IMASATO et al., 2017; SHIGAKI, 2013). Caso o pesquisador não atenda aos requisitos exigidos pela avaliação institucional da CAPES no programa, ele pode ser substituído por um outro pesquisador que tenha um número de produção científica e que atenda a pressão institucional gerada pelo programa local. Nesse contexto, entendemos que essa pressão institucional gerada pelo programa local é reflexo de uma (c) (1) $(9$ 
influência social exercida sobre o pesquisador. Servindo como base para a nossa primeira hipótese:

\section{Hipótese 1 - Quanto maior o grau de produtivismo do programa de pós-graduação} que o pesquisador atua, maior o grau de produtivismo do pesquisador.

Quando os autores se propõem a escrever um artigo em coautoria com outros pesquisadores, eles precisarão levar em conta alguns gastos, tais como custos para encontrar um parceiro ideal, custos para organização da equipe, tendo em vista que essa equipe precisará culminar em bons resultados e escolher quais serão os membros que farão parte dessa produção e qual o custo para conseguirem alcançar uma equidade de pensamento. Ou seja, precisarão de alguma tecnologia para conseguirem cooperar - em casos de pesquisadores que estão em outros estados, cidades, ou países - e terão custos para conseguirem ter uma relação de confiança com os coautores (GULATI, 1995; INKPEN et al., 2005).

Portanto, espera-se que os pesquisadores prefiram continuar trabalhando com pessoas que já trabalharam alguma vez, pois, para iniciar um novo laço de relação, eles precisarão arcar com esses custos listados anteriormente (LARSON, 1992). Além disso, os pesquisadores que já estão em um processo de parceria, já compartilharam, em algum momento, todos os custos necessários para o desenvolvimento do projeto de pesquisa. Desse modo, espera-se que pesquisadores que já possuem relacionamentos mais consistentes, tendam a publicar mais (REAGANS et al., 2003). Nesse contexto, tal raciocínio reflete diretamente na nossa próxima hipótese:

\section{Hipótese 2 - Quanto maior o grau de produtivismo dos coautores, maior o grau de} produtivismo do pesquisador.

A competitividade de produção científica é estimulada de acordo com o número de artigos publicados em um determinado período, tendo em vista que, para concorrerem aos editais de fomento de pesquisa e serem contemplados, os pesquisadores precisam ter uma determinada quantidade de produção científica (REGO, 2014). Desse modo, é feito um ranqueamento para contemplar os pesquisadores que atendem a esse determinado número. Se os pesquisadores possuem um maior número de publicações, a competividade tende a aumentar e, junto com a competividade, aumenta, também, o número de publicações (IMASATO et al., 2017). Além disso, essa ideia ressalta a proposta do publicar ou perecer, expressão que deu 
origem ao produtivismo acadêmico, pois, para se manter dentro do mainstream acadêmico, o pesquisador precisa ter um determinado número de artigos publicados em revistas indexadas (HORTA; SANTOS, 2016). Nesse contexto, o aumento de competitividade de número de publicações realizadas em periódicos indexados no âmbito acadêmico culmina em um período com um alto volume de produção de artefatos acadêmicos. Tal raciocínio direciona à nossa terceira e última hipótese:

Hipótese 3 - Quanto maior a média de produção de um período, maior o grau de produtivismo do pesquisador.

\section{PROCEDIMENTOS METODOLÓGICOS}

Esta pesquisa foi elaborada dentro do paradigma pós-positivista com uma abordagem de métodos mistos (DENZIN; LINCOLN, 2017; LEAVY, 2017). Nesse sentido, realizamos uma etapa qualitativa e outra quantitativa que ocorreram, concomitantemente, entre os meses de setembro e dezembro de 2019.

Em relação ao corte temporal, a pesquisa pode ser considerada longitudinal, visto que foram analisados os dados completos disponíveis desde a última avaliação CAPES, em 2013, consistindo no período de 2013 a 2018 (FREITAS et al., 2000). Considerando esse período, buscamos analisar as mudanças quanto às variáveis com o tempo.

A análise quantitativa utilizou a abordagem de Análise de Redes Sociais e a regressão linear, pois procurou-se analisar o efeito direto de como o produtivismo acadêmico influencia em três aspectos, sendo: (i) na relação programa x pesquisador; (ii) na relação rede de coautoria x pesquisador; (iii) na relação de período produtivista $\mathrm{x}$ pesquisador.

Essa fase foi elaborada em algumas etapas: (i) levantamento com todos os programas de pós-graduação em Administração que são cadastrados e reconhecidos pela CAPES no período de 2013 a 2018; (ii) coleta de dados, com a produção em revistas indexadas dos pesquisadores que estão associadas aos programas de pós-graduação em Administração no período de 2013 a 2018, que estejam situados nos estados do Rio Grande do Sul, São Paulo e Rio de Janeiro por meio do currículo cadastrado na Plataforma Lattes, tento esta sido feita pela ferramenta Extrator Lattes; (iii) elaboração da estrutura de relações entre os pesquisadores dos diferentes programas de pós-graduação em Administração no período de 2013 a 2018, utilizando o software R versão 3.5; (iv) análise de como o produtivismo acadêmico altera o seu comportamento de acordo com a relação entre a rede de coautoria x pesquisador, período 
produtivista x pesquisador, compreendendo o período entre 2013 a 2018. A análise de dados foi realizada por meio do software R versão 3.5.

Por outro lado, a análise qualitativa foi realizada por meio de entrevistas semiestruturadas, visando captar as opiniões de pesquisadores que fazem parte desses programas de pós-graduação, buscando aumentar a discussão sobre os dados coletados quantitativamente. Convidamos dez professores que fazem parte de programas de pósgraduação com conceito capes 5, 6 ou 7. Entretanto, somente três professores aceitaram o convite para entrevista, sendo dois de universidades no estado do Rio de Janeiro, um de universidade privada e um de universidade pública; e um do estado de São Paulo, também de universidade pública.

As entrevistas foram feitas presencialmente e, quando a entrevista presencial não foi possível, foi feita a entrevista através do Skype, todas as três entrevistas foram gravadas e, posteriormente, transcritas, tendo duração de, aproximadamente, duas horas de gravação.

A análise das entrevistas se deu através da análise de conteúdo (BARDIN, 1977), examinando os elementos que foram considerados cerne para as categorias analíticas. Segundo Leite (2017), o roteiro de entrevista semiestruturado com o uso da análise de conteúdo permite ampliar a discussão das categorias analíticas. Os pontos de análise foram: a concepção de produtivismo dos entrevistados, os fatores que podem influenciar essa prática, as consequências do produtivismo para a produção científica e a relação entre os pesquisadores, como se dava a consolidação de novas parcerias, como a parceria entre pesquisadores renomados poderia alavancar a carreira de novos pesquisadores, como o contato de pesquisadores produtivistas com novos pesquisadores poderiam impactar as suas carreiras como pesquisadores. Na próxima seção, apresentamos os resultados das duas fases de análise em conjunto.

\section{ANÁLISE E RESULTADOS}

\subsection{PERFIL DA AMOSTRA E DOS RESPONDENTES}

A construção do trabalho se deu com o objetivo de identificar como funciona o produtivismo acadêmico na área de administração, a fim de reconhecer fatores sociais que podem alavancar o volume de produtivismo dentro do meio acadêmico de acordo com dados retirados da Plataforma Lattes. Além disso, foram entrevistados três professores que fazem parte dos programas de pós-graduação analisados: dois de programas de pós-graduação do 
estado do Rio de Janeiro, sendo um pesquisador de universidade pública e um de universidade privada, e um do estado de São Paulo, pesquisador de universidade pública.

Inicialmente, foram descritas as informações coletadas dos 453 pesquisadores referentes a dados básicos, tais como: área de atuação, produção bibliográfica, autores e coautores e orientações, com o objetivo de entender o perfil, nacionalidade e a instituição em que o pesquisador atua. Pela Tabela 1, é possível observar que, entre os 453 pesquisadores avaliados neste trabalho, a grande maioria tem o Brasil como país de nacionalidade $(96,03 \%)$, assim como o país de trabalho $(94,92 \%)$. Destaca-se que mais de $20 \%$ dos pesquisadores trabalham na Universidade de São Paulo, quase metade deles trabalha no estado de SP (47,24\%), dos quais 38,63\% trabalham na cidade de São Paulo. Ou seja, a grande concentração dos programas de pós-graduação está situada na cidade de São Paulo.

Tabela 1 - Distribuição de frequências dos dados básicos dos pesquisadores incluídos no estudo

\begin{tabular}{|c|c|c|}
\hline Variável & Frequência absoluta & $\%$ \\
\hline \multicolumn{3}{|l|}{ País de nacionalidade } \\
\hline Brasil & 435 & $96,03 \%$ \\
\hline Alemanha & 2 & $0,44 \%$ \\
\hline Peru & 2 & $0,44 \%$ \\
\hline Portugal & 2 & $0,44 \%$ \\
\hline Outros & 11 & $2,43 \%$ \\
\hline Não informado & 1 & $0,22 \%$ \\
\hline \multicolumn{3}{|l|}{ Instituição de trabalho } \\
\hline Universidade de São Paulo & 98 & $21,63 \%$ \\
\hline Universidade Federal do Rio de Janeiro & 42 & $9,27 \%$ \\
\hline Universidade Federal do Rio Grande do Sul & 42 & $9,27 \%$ \\
\hline Universidade Federal Fluminense & 31 & $6,84 \%$ \\
\hline Fundação Getúlio Vargas - SP & 27 & $5,96 \%$ \\
\hline Universidade do Vale do Rio dos Sinos & 25 & $5,52 \%$ \\
\hline Universidade Nove de Julho & 22 & $4,86 \%$ \\
\hline Fundação Getúlio Vargas - RJ & 21 & $4,64 \%$ \\
\hline Pontifícia Universidade Católica do Rio de Janeiro & 21 & $4,64 \%$ \\
\hline Universidade Presbiteriana Mackenzie & 15 & $3,31 \%$ \\
\hline Escola Superior de Propaganda e Marketing & 13 & $2,87 \%$ \\
\hline Universidade do Grande Rio & 12 & $2,65 \%$ \\
\hline Faculdade de Economia, Administração e Contabilidade - USP & 11 & $2,43 \%$ \\
\hline Pontifícia Universidade Católica do Rio Grande do Sul & 10 & $2,21 \%$ \\
\hline Universidade do Estado do Rio de Janeiro & 10 & $2,21 \%$ \\
\hline Outras & 53 & $11,70 \%$ \\
\hline
\end{tabular}

Fonte: Elaborado pelo autor (2021). 


\subsection{PRODUÇÃO INTELECTUAL DOS PESQUISADORES E REDE DE COAUTORIA}

Pela Tabela 2, nota-se que, dos 82.004 itens de produção bibliográfica avaliados entre os 453 pesquisadores, $35,95 \%$ se referem a trabalhos em eventos e $29,14 \%$ a textos em jornal ou revista. Ainda, vê-se que há um total de 18.350 artigos publicados, que correspondem a 22,38\% das publicações, sendo tal tipo de produção considerado para avaliação do produtivismo dos pesquisadores. Observa-se um aumento expressivo na produção de publicações realizadas em periódicos, uma vez que a avaliação realizada pela CAPES não considera como pontuação a publicação realizada em eventos. E é algo que também é ressaltado durante a entrevista realizada com o entrevistado 1 :

O indivíduo pode optar por não ser produtivista, entretanto, não conseguirá obter
emprego, então, de fato, não é uma opção. Porque existe uma necessidade do
pesquisador de sobreviver e arcar com suas despesas pessoais. Talvez um
pesquisador que esteja em uma instituição pública, com algum grau de estabilidade
pode fazer essa opção, mas mesmo assim com algumas restrições, pois, mesmo
estando em uma instituição pública com estabilidade, caso você não obtenha o
número de produçôes desejada normativamente, e estiver lecionando em curso de
mestrado e doutorado, você poderá ser descredenciado. (E1)

Observa-se que, no relato do entrevistado, não existe a opção de um pesquisador credenciado a um programa de pós-graduação na área de Administração escolher por não ser produtivista - uma vez que praticamente $80 \%$ da avaliação quadrienal da instituição é dada pela produção científica realizada, seja essa produção feita pelo corpo discente, seja feita pelo corpo docente. Desse modo, o risco de o pesquisador aderir a essa prática produtivista é enorme, pois caso ele não se submeta, o pesquisador se põe em uma posição de risco, visto que os outros pesquisadores que fazem parte desse mesmo programa vão continuar publicando. Nesse sentido, Imasato et al. (2017) se refere a essa necessidade e como se tornou o lema "publish or perish", para ilustrar essa realidade de que, ou o pesquisador se rende a esse sistema mainstream, ou será expulso dele (HORTA; SANTOS, 2016). Isso acaba gerando uma concorrência muito acirrada entre os pesquisadores, resultando em uma maior competitividade (REGO, 2014). Durante as entrevistas, alguns pesquisadores ressaltaram que as instituições oferecem prêmios como viagens para congressos internacionais, prêmios em dinheiro, promoção, entre outros, de acordo com o Qualis CAPES daquela determinada publicação, pressionando o pesquisador a buscar estratégias para conseguir estar bem posicionado e obter esses prêmios. Tais afirmações vão ao encontro do argumento sobre competitividade colocado por Imasato et al. (2017). 
Além disso, a entrevistada 2 ressaltou que o pesquisador que trabalha com a metodologia quantitativa consegue obter vantagem sobre o pesquisador da área qualitativa, pois ele geralmente trabalha com um modelo estatístico que, se estiver bem modelado, pode se transformar em vários artigos científicos, basta ele somente alterar as variáveis daquela pesquisa. Já o pesquisador que trabalha com a metodologia qualitativa teria mais trabalho para realizar suas análises e gastaria mais tempo para produzir seus artigos. Sendo assim, é necessário que sejam criadas diretrizes de avaliações diferentes para pesquisas publicadas com abordagens quantitativa e qualitativa, não esquecendo, ainda, das pesquisas que trabalham com as duas abordagens.

Quanto ao país da publicação, observa-se que, para 20,73\% dos itens o país não foi informado, mais de dois terços $(68,32 \%)$ foram publicados no Brasil, e os 10,95\% restantes estão distribuídos entre outros países. O idioma predominante das publicações é o português $(82,03 \%)$, seguido do inglês $(15,99 \%)$.

O número expressivo na publicação de artigos indexados nos periódicos brasileiros, segundo a entrevistada 2 , deve-se à parceria entre autores e editores. Isso impede que a publicação na área de Administração ocorra, em maior número, em revistas internacionais. Uma prática que, segundo ela, distancia a academia brasileira do restante do mundo.

No entanto, vemos essa parceria entre autores e editores como resultado do que já foi discutido na literatura: pesquisadores tendem a trabalhar com profissionais com quem já estabeleceram relações de confiança e que não exijam altos custos para uma nova produção (GULATI, 1995; INKPEN et. al., 2005; LARSON, 1992).

Certamente, eu acho que têm redes de colaboração que são fruto de coleguismo, sendo assim, se você pegar algumas revistas brasileiras e for fazer uma análise de quem publica ali, são os amigos, e claro que são sempre os mesmos. E esse tipo de rede impacta no produtivismo acadêmico e não ajuda o pesquisador a crescer. (E2)

Essa parceria entre autores e editores aumenta o produtivismo acadêmico e amplia o conhecimento da área de Administração a nível local, mas dificulta o incentivo à publicação em outros idiomas, uma vez que os programas inerentes no escopo da pesquisa são os principais programas na área de Administração de acordo com a última avaliação quadrienal da CAPES. A internacionalização das pesquisas realizadas no Brasil fomenta possibilidades de ampliar o alcance dos pesquisadores brasileiros e é notável que a maioria dos pesquisadores brasileiros prefere publicar seus artigos em revistas nacionais, soando como um coleguismo, conforme expressado pela entrevistada 2 . 
Contudo, segundo Bertero et al. (2013), passaríamos de simples compradores de teorias internacionais para fornecedores de teorias, ajudando a inserir o contexto nacional para as principais teorias que são debatidas nos congressos e revistas internacionais; saindo do pressuposto de um simples adquirente de teoria "pré-produzida". Outrossim, existem outros fatores que influenciam a aceitação de artigos nacionais em revistas internacionais. Um problema proveniente do colonialismo acadêmico, pois os avaliadores internacionais tendem a rejeitar a produção de artigos nacionais devido ao uso de somente teorias de natureza anglosaxônica (BERTERO et al., 2013).

Sob esse ponto de vista, publicar na língua portuguesa em periódicos brasileiros atende a necessidade de produção exigida ao pesquisador, pois também existem periódicos que possuem o Qualis CAPES alto, trazendo retorno de valor para o pesquisador em sua pontuação. Além disso, o pesquisador brasileiro geralmente conhece os editores das revistas que possuem Qualis CAPES e, muitas vezes, usam do coleguismo para publicar nessas revistas. Desse modo, ele fica desestimulado em publicar em revistas internacionais, pois, de todo modo, vai receber a mesma pontuação ou até, às vezes, a pontuação maior do que se publicasse em uma revista internacional, considerando, ainda, que, para tal, serão necessários gastos com traduções e revisões para língua estrangeira, gerando um gasto extra. Ademais, os leitores das revistas internacionais buscam um conteúdo que seja adequado e abrangente para utilizá-los ou adaptálos em suas realidades. Já os leitores de revistas nacionais buscam teorias que foram aplicadas em contexto nacional e que, dependendo do contexto, podem ser de conteúdo mais difícil de ser adaptado à cultura de outros países em uma abordagem empírica (REGO, 2014).

Tabela 2 - Distribuição de frequência das produções bibliográficas dos pesquisadores incluídos no estudo

\begin{tabular}{lcc} 
Variável & Frequência absoluta & \% \\
\hline Tipo de produção & & $35,95 \%$ \\
\hline Trabalho em eventos & 29.479 & $29,14 \%$ \\
Texto em jornal ou revista & 23.894 & $22,38 \%$ \\
Artigo publicado & 18.350 & \\
\hline País & & $68,32 \%$ \\
Brasil & 56.026 & $3,43 \%$ \\
Estados Unidos & 2.810 & $0,77 \%$ \\
Portugal & 635 & $0,50 \%$ \\
Espanha & 413 & $0,44 \%$ \\
França & 358 & $0,41 \%$ \\
Argentina & 339 & $0,40 \%$ \\
México & 324 & $0,38 \%$ \\
Grã-Bretanha & 315 & $0,37 \%$ \\
Chile & 307 & $4,24 \%$ \\
Outros & 3.480 &
\end{tabular}


Não informado

\section{Idioma}

Português

Inglês
16.997

67.268

$82,03 \%$

13.110

$15,99 \%$

Fonte: Elaborado pelo autor (2021).

Pela Tabela 3, nota-se que, entre as 69.725 publicações avaliadas na seção de autores e coautores, em $73,09 \%$, o pesquisador em questão ocupava a primeira posição na ordem de autoria, enquanto que, em 26,63\% dos trabalhos, a posição ocupada era a segunda. Ainda, no total, mais de $80 \%$ das publicações possuem até três autores. Observa-se que, na rede de coautoria, os pesquisadores que fazem parte dos programas de pós-graduação costumam ocupar os primeiros lugares da ordem de autoria.

Todos os entrevistados compreenderam que o problema do produtivismo é complexo e que os estímulos para a produção científica são importantes. Porém, na situação em que o volume de produção é supervalorizado, o resultado é focado na quantidade de produções e não na qualidade delas, o que compromete a produção acadêmica.

Tabela 3 - Distribuição de frequência dos autores e coautores das produções dos pesquisadores incluídos no estudo

\begin{tabular}{ccc} 
Variável & Frequência absoluta & $\%$ \\
\hline Ordem de autoria & & $73,09 \%$ \\
\hline 1 & 50.961 & $26,63 \%$ \\
\hline 2 & 18.567 & $11,53 \%$ \\
\hline 3 & 8.039 & $3,98 \%$ \\
\hline 4 & 2.773 & $0,93 \%$ \\
\hline 5 & 651 & $0,19 \%$ \\
\hline 6 ou mais & 134 & $26,89 \%$ \\
\hline Número de autores & & $31,71 \%$ \\
\hline 1 & 18.751 & $22,15 \%$ \\
\hline 2 & 22.109 & $12,22 \%$ \\
\hline 4 & 15.444 & $3,71 \%$ \\
\hline 5 & 8.520 & \\
\hline
\end{tabular}

Fonte: Elaborado pelo autor (2021).

Na Figura 2, é apresentada a série temporal da produtividade dos pesquisadores em que foi considerado, como métrica, o número de produções bibliográficas do tipo artigo publicado por pesquisador e calculada a produtividade média entre os pesquisadores em cada ano (os anos de 2019 e 2020 foram desconsiderados por não estarem completos no momento da análise). 
Figura 2 - Série anual da produtividade média dos pesquisadores incluídos no estudo

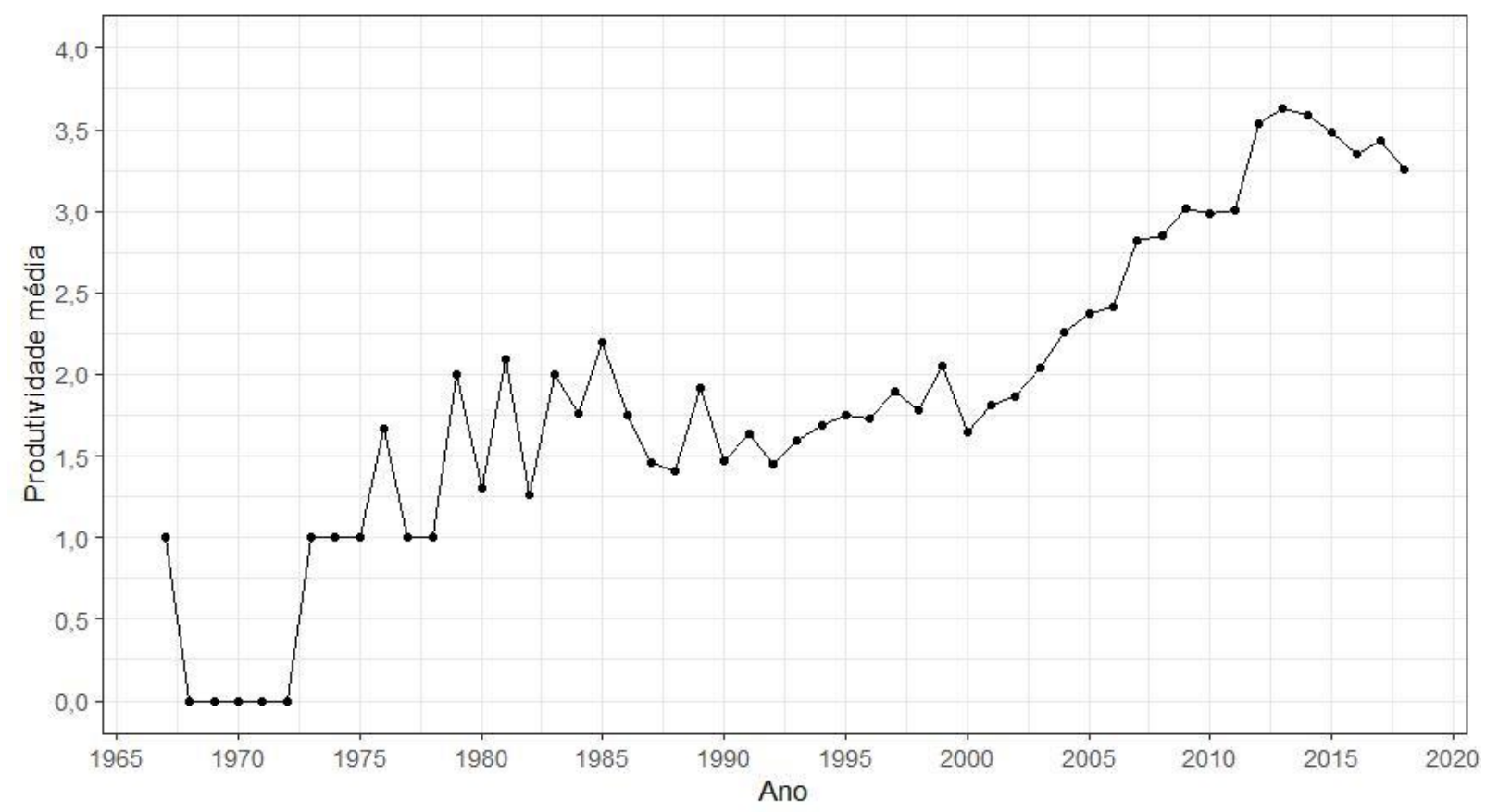

Fonte: Elaborado pelo autor (2021).

Avaliando a Figura 2, que apresenta o comportamento temporal da série anual da produtividade média dos pesquisadores, observa-se que, sempre ao início de um quadriênio, existe um aumento no volume da produção científica, ilustrando uma tabela de pontos da avaliação CAPES que obriga o pesquisador a se preocupar com a pontuação alcançada durante o período de avaliação, fato corroborado com os dados da entrevista realizada com o entrevistado 1.

Certamente existe uma prática de otimização no número de produções, pois, se você realiza diversas publicações, você acaba ficando descoberto, até mesmo porque a produção não é medida somente pelo número de produções, ela também é medida pela distribuição em periódicos com um determinado extrato da Qualis CAPES. (E1)

Essa cadência na estratégia por publicação é trazida pelo entrevistado $1 \mathrm{e}$, posteriormente, confirmada pela entrevistada 2, quando ela afirma que os dois primeiros anos do quadriênio vão ditar o comportamento do pesquisador no restante do quadriênio, visto que ele precisa identificar se já conseguiu atender o número mínimo de publicações qualificadas para manter a sua posição de trabalho e o seu prestígio.

Os dois primeiros anos do quadriênio estabelecem a regra do jogo, eles vão trazer uma visibilidade muito boa de como está cada um dos programas e o que vem depois disso é ponto extra. (E2) 
Essa prática de pensar na produção científica como mercadológica pode ocasionar em diversos problemas, pois ao invés do processo de produção científica fazer parte ativamente de um processo de ensino, passa, simplesmente, a ser considerado como um simples processo de negócio, com o intuito de possibilitar ao pesquisador um diferencial competitivo e um meio de se manter vivo, publicando (ALCADIPANI, 2011). Desse modo, depois que o pesquisador atinge o máximo de pontos para receber a maior pontuação naquele quadriênio, ele aguarda o próximo quadriênio para realizar novas publicações, assim ele vai se mantendo dentro desse sistema de pontos.

Tabela 4 - Resultado do teste de Mann-Kendall da série anual da produtividade média dos pesquisadores incluídos no estudo

\begin{tabular}{cc}
\hline Tau & P \\
\hline 0,743 & $<0,001^{*}$ \\
\hline
\end{tabular}

$*$ Valor $\mathrm{p}<0,05$

Fonte: Elaborado pelo autor (2021).

Conforme a Tabela 4, que apresenta os resultados da aplicação do teste não-paramétrico de Mann-Kendall à produtividade média, há evidências amostrais suficientes de existência de tendência significativa, ao nível de 5\% de significância, sendo uma tendência positiva, dado o sinal do coeficiente tau $(0,743)$, indicando um aumento da produtividade média ao longo do período.

Na Figura 3, são apresentadas as correlações da produtividade individual e da instituição de trabalho e da produtividade individual com o número de colaborações da instituição de trabalho. 
Figura 3 - Diagrama de dispersão da produtividade média por instituição e individual dos pesquisadores incluídos no estudo

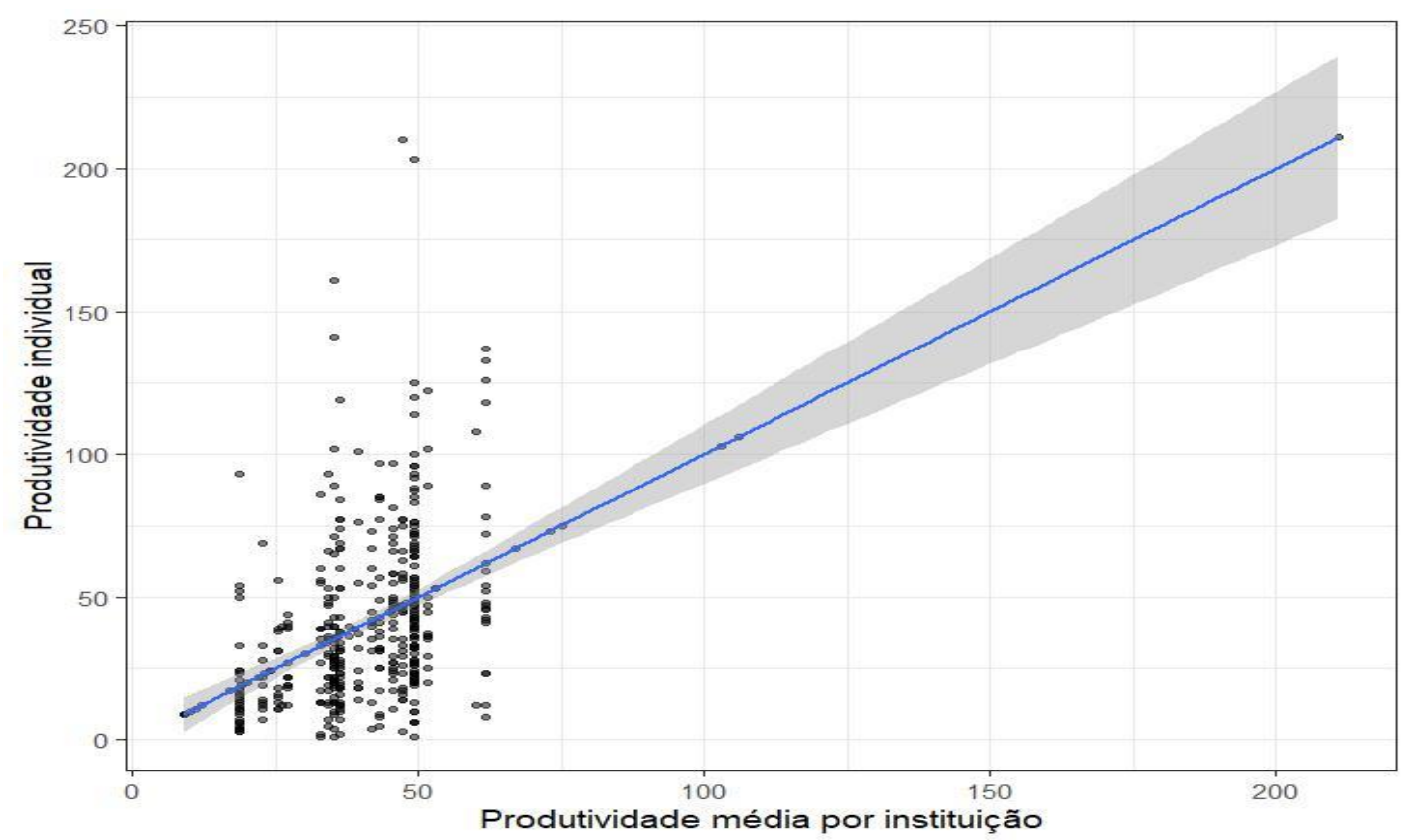

Fonte: Elaborado pelo autor (2021).

Vê-se, na Figura 3, que quanto maior a produtividade média da instituição de trabalho, maior tende a ser a produtividade individual dos pesquisadores avaliados, resultado corroborado pelo teste de correlação de Spearman, o qual indicou uma correlação significativa entre ambas as métricas (ao nível de 5\% de significância (valor $\mathrm{p}<0,001$ ), com coeficiente de correlação de 0,45 .

A produtividade média realizada por uma determinada instituição influencia diretamente na produção realizada por um pesquisador durante um determinado período, elevando, consequentemente, o número de produções realizadas por aquele pesquisador durante um determinado período. Isso se deve à competividade interna dos pesquisadores que pertencem a esses programas e também à competividade externa, pois, segundo o que foi relatado pelo entrevistado 1, as instituições acompanham o desempenho de pesquisadores que fazem parte de outros programas.

Os programas de pós-graduação que estão mais bem colocados tendem a influenciar os pesquisadores a elevar o número de produções, pois pode ser algo como um benchmarking, os programas costumam analisar o que os outros programas estão fazendo, e faz sentido pensar assim. As escolas procuram sugerir fortemente que seus professores tenham um nível não equivalente, mas compatível de produções. Já ouvi dizer que algumas escolas procuram fomentar esse tipo de situação entre os seus professores. Até porque ela tem mecanismos para isso, ela pode oferecer prêmios, ou ameaçar o pesquisador de demissão. (E1) 
Fato que corrobora o que Noah Friedkin traz, através da teoria da influência social, pois o pesquisador demonstra uma alteração de comportamento, uma vez que, por estar inserido dentro daquele determinado grupos sociais, ele precisa ajustar os seus comportamentos para conseguir acompanhar a produção dos demais pesquisadores que fazem parte daquele programa de pós-graduação. Todas essas ações são manifestadas por meio de uma rede social de influência (FRIEDKIN, 1998). Essa rede fica responsável por incentivar a produção individual, pois o pesquisador que está desalinhado com essa prática pode sofrer danos, como: perder bolsas, prêmios, ser demitido, ser descredenciado do programa, entre outras punições. Desse modo, essa prática se torna uma obrigação e não apenas uma opção. É importante ressaltar que não há só uma competição dentro da organização, pois essa competição ganha patamares ainda maiores e se torna uma competição nacional pelas melhores publicações e, consequentemente, pelas melhores notas de acordo com sistema de avaliação CAPES.

Tais resultados apontam que a busca por um maior número de publicações está relacionada à manutenção deste pesquisador dentro de um grupo seleto de pesquisadores que também tende a aumentar a competitividade (HORTA; SANTOS, 2016; IMASATO et al., 2017).

Nesse contexto, todos os entrevistados reconheceram o protagonismo da CAPES nessa disputa, pois, de forma normativa, eles impõem quais serão os parâmetros de avaliação, ocorrendo diversas mudanças de acordo com cada avaliação quadrienal ou trienal.

A Figura 4 apresenta a rede de coautoria obtida para o grupo em análise. Entre os 453 pesquisadores, 416 apresentaram colaborações entre si, denominados vértices isolados - porque pesquisadores sem coautoria com outros do grupo não foram diagramados -, em um total de 11.380 trabalhos denominados arestas. 
Figura 4 - Representação da rede de coautorias entre os pesquisadores incluídos no estudo

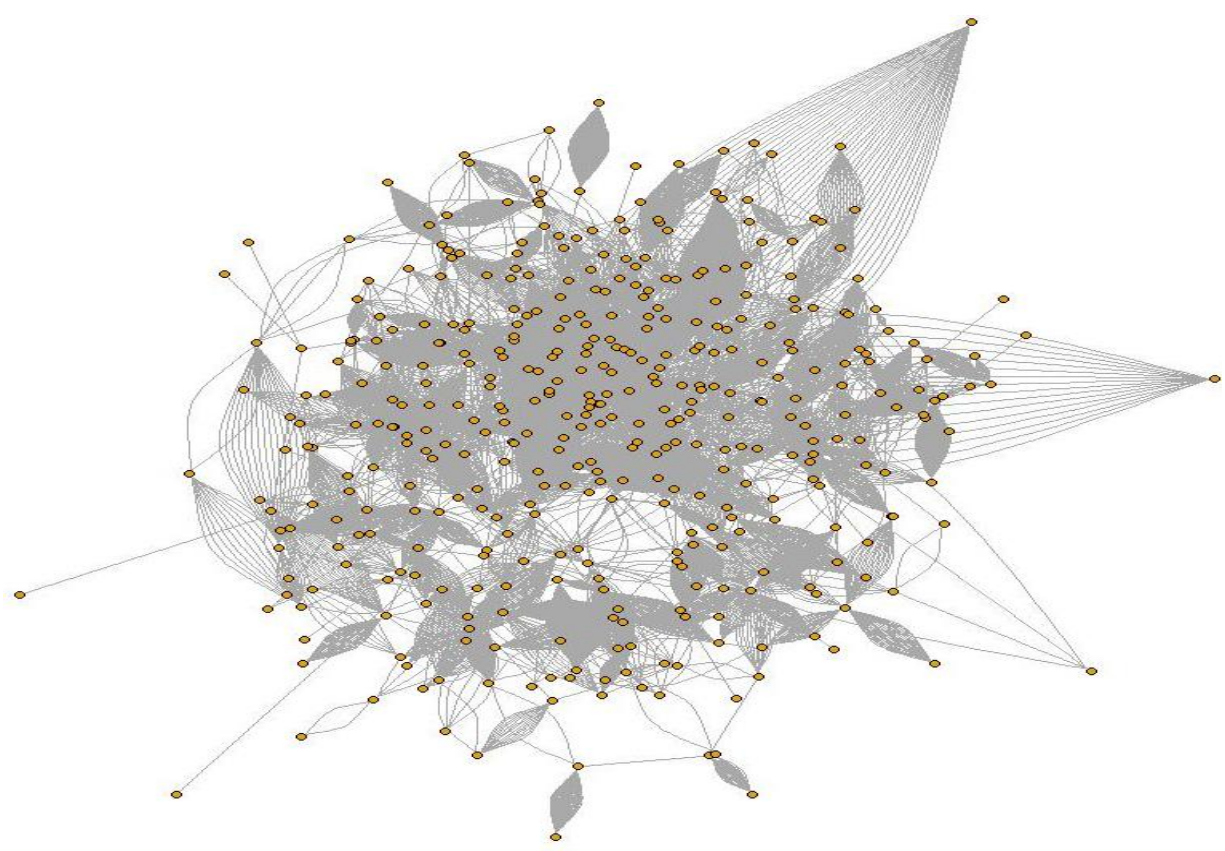

Fonte: Elaborado pelo autor (2021).

Em média, cada pesquisador mantém colaboração com 3,96 pesquisadores. Destacandose que houve duplas de pesquisadores que produziram até 201 trabalhos em conjunto, a média de produções entre as duplas que já trabalharam juntas é de 10,13 trabalhos. Esse aumento na recorrência de colaboração entre os mesmos coautores, de acordo com o entrevistado 1, se deve ao fator confiança, e da consolidação do estabelecimento da rede de confiança.

Eu não trabalharia com quem eu não tenha confiança, conheço pessoas que me propuseram parceria, mas, devido a não ter uma relação de confiança com aquela pessoa, eu não dividi a produção com ela, já aconteceu de parar de trabalhar com uma pessoa pela questão da confiança. Fiz um artigo em parceria com ela, e, quando fomos para a segunda produção, notei que não teria mais condições daquela parceria continuar. (E1).

A relação de confiança demonstrada pelo entrevistado 1 é confirmada pelo entrevistado 3, uma vez que realmente é indispensável para a boa consolidação dessa rede que a parceria dessa dupla ou trio de pesquisadores ocorra da melhor forma possível, para garantir o sucesso de futuros trabalhos.

É difícil formar uma parceria, então é necessário pensar em uma forma de trabalhar junto com confiança. Em que as pessoas realmente vão trabalhar nos projetos, a parceria principalmente entre professores, e, consequentemente, os pesquisadores tendem a fazer vários trabalhos juntos, porque isso é natural, porque são pessoas que estão com o mesmo interesse de pesquisa, e fazem vários trabalhos ao longo do tempo, na mesma parceria. (E3) 
Tais resultados apontam a importância da confiança para construção de uma rede colaborativa de produção, como ilustrado pela Figura 4 e confirmado pelas falas dos entrevistados 1 e 3 . A confiança na parceria é representada pela maior densidade da rede, que também é demonstrada pelo desempenho dessas parcerias (COLEMAN, 1988; FLEMING et al., 2007).

Por outro lado, um dos problemas relevantes causados pela alta demanda por produtividade é a prática de coautorias indevidas e abuso da rede de parcerias, de acordo com os entrevistados. Nesse contexto, eles explicam que, para aumentar o número de artigos que se publica em revistas indexadas, os pesquisadores inserem o nome de outros pesquisadores parceiros em seus artigos, em troca de ter os seus nomes adicionados em outros; prática que o entrevistado 3 denominou de "parcerias fantasma". Essa "parceria", na verdade, só tende a prejudicar os pesquisadores que trabalham de forma honesta, pois essas condutas podem aumentar o volume de produção de um determinado pesquisador em detrimento do número de produções que ele teve em um determinado quadriênio. Segundo McNutt et al. (2018), é urgente que os periódicos padronizem o sistema de autoria de forma a tornar esse sistema não só único e conhecido por todos, mas que o sistema seja padronizado de forma a garantir essa transparência sobre as publicações. E que, além disso, os autores tenham ética e transparência em suas produções, reconhecendo o que ele produziu.

Com o objetivo de ajudar pesquisadores que, em algum momento da sua carreira, já cometeram algum tipo de deslize no que tange à legalidade científica em sua carreira, nos EUA foi criado um programa de reabilitação científica, denominado Restoring Professonalism and Integrity in Reseach (RePAIR). A sua estrutura é similar a um centro de recuperação para dependentes químicos, possuindo um preço alto, custando, por três dias, o valor de US\$ 3 mil (REGO, 2014). Seria interessante pensar em algo parecido em um contexto nacional. Levando em consideração a cultura local, essa medida poderia ser uma solução paliativa para aumentar a reputação brasileira na comunidade científica internacional.

Além disso, segundo os entrevistados, é importante que os pesquisadores e instituições de pesquisa pressionem os periódicos e a CAPES a adotarem medidas e regras para garantir essa transparência e, com isso, mitigar a pressão do produtivismo gerado a partir de notas e resultados consequentes de uso indevido de coautoria e coleguismos. Pensar, também, em aumentar o percentual de avaliação em outros meios como: publicações em periódicos estrangeiros, alinhamento da academia e o setor produtivo nacional e internacional, número de discentes que conseguiram realizar mestrado/doutorado sanduíche durante os seus estudos, entre outros mecanismos que vão, sem dúvida, incentivar os pesquisadores e discentes a 
obterem uma formação na qual não serão obrigados a terem que produzir um número elevado de artigos em revistas indexadas para comprovarem que possuem as melhores notas da avaliação CAPES.

\section{CONSIDERAÇÕES FINAIS}

O objetivo deste artigo foi identificar como o grau de imersão em processos sociais de influência pode aumentar o produtivismo acadêmico em pesquisadores da área de Administração. Para tanto, recorreu-se à teoria da influência social (FRIEDKIN, 1998; FRIEDKIN, 2003) e estruturas de redes sociais (ABRAMO et al., 2011; BURT, 2017; GONZALEZ-BRAMBILA et al., 2013; SERRAT, 2017). Constatou-se que a influência social, observada por meio das estruturas de redes sociais, direciona a produção científica na área de Administração gerando um produtivismo acadêmico como resposta a uma pressão normativa e institucional para que se produza uma determinada quantidade de produção científica.

O produtivismo acadêmico vem se consolidando, ao longo dos anos, como uma prática comum na academia. Por meio dos dados obtidos durante esta pesquisa, observou-se que a produção de um alto volume de artigos científicos, que é produzida por uma determinada instituição, influencia diretamente no aumento da produção individual de cada pesquisador, fato que confirma a primeira hipótese aqui proposta. Esse aumento de produção acontece devido a um efeito cascata, uma vez que, para se manter em um programa com um alto volume de produção científica, o pesquisador precisa, também, ter um determinado número de produção, mesmo que ele já tenha obtido o número mínimo de produção científica para manter a atual nota do programa de pós-graduação ao qual está associado. Tal prática demonstra o quanto o produtivismo acadêmico está enraizado na academia, principalmente no que diz respeito à produção intelectual dos pesquisadores associados a programas de pós-graduação, pois esse fato de a produção do programa reverberar na produção individual denota que existe uma competição interna entre os pesquisadores para conseguir saber qual pesquisador possui o maior número de produções.

É importante ressaltar que, nas três entrevistas, os entrevistados mencionam o produtivismo como sendo uma prática nociva, tanto para a produção intelectual quanto para os pesquisadores, que precisam se render a esse "sistema", caracterizando-o como uma busca incessante ou mesmo obsessiva de produção, e tendo como principal crítica o fato de que, nesse sistema, se dá mais valor à quantidade produzida do que à qualidade da produção. Nesse 
contexto, isso se torna extremamente ruim para ciência brasileira, e corrobora com a teoria da influência social, uma vez que os pesquisadores tendem a ter a mesma postura de busca por publicações apenas com o objetivo de estar bem posicionado naquele determinado nicho, o que, diretamente, dita como os novos pesquisadores que estão ingressado nessa área tendem a se posicionar. Assim, tem-se uma busca de posições consolidadas em assuntos que, muitas vezes, são incrementais, tornando-se um ciclo vicioso e uma prática para a divulgação científica brasileira, principalmente em uma área tão importante para as Ciências Sociais Aplicadas como a Administração.

Ademais, a rede de coautoria nos programas de pós-graduação que estão no escopo desta pesquisa é explicitada de maneira consistente, uma vez que apresenta alto volume em sua densidade, demonstrando que os pesquisadores de diferentes estados utilizaram o artifício da rede de colaboração para aumentar a sua produção individual. Ainda, observa-se que os autores que fazem parte da rede de coautoria aparecem sempre como primeiro, segundo ou terceiro autor do artigo publicado em periódico. Nesse sentido, observa-se que mesmo quando um periódico adota medidas restritivas, como diminuir o número de autores de um artigo, limitando a três autores, eles vão continuar com o mesmo volume de produção, pois, dentro da produção intelectual, observa-se que os pesquisadores ocupam posições centrais. Esse aumento do produtivismo acadêmico, devido à construção das redes de coautoria, confirma a segunda hipótese proposta por esta pesquisa. É importante ressaltar que existe uma minoria de pesquisadores que não utilizam essa rede para aumentar a sua produção individual. Para futuras pesquisas, seria interessante analisar se esses pesquisadores, que não estão contribuindo com a prática de colaboração dentro desses programas, estão inclusos em outras redes de coautoria, relacionadas a outras áreas, ou, talvez, a pesquisadores de outros países.

No ano de 2013, observa-se um aumento da produção média de artigos publicados em revistas indexadas, tendo em vista todos os programas que estão no escopo desta pesquisa. Já no ano de 2014, observa-se o declive na produção média dos programas, também notada nos anos posteriores (2015 e 2016). Em 2017, tem-se um aumento na produção; esse aumento se deve ao início do novo quadriênio. Já no ano de 2018, existe um número produzido muito menor. Observa-se que, no início de um quadriênio, existe um aumento de produção de artigos publicados em periódicos por parte dos pesquisadores, volume que vai diminuindo nos anos posteriores ao primeiro ano do quadriênio. Essa diminuição se deve a uma administração dos artigos produzidos pelos pesquisadores, pois, conforme relatado em entrevista, se os pesquisadores publicarem todos os artigos produzidos, talvez possa acontecer de ficarem sem artigos para publicarem nos anos subsequentes do período de escopo da próxima avaliação 
quadrienal. Isso confirma a terceira e última hipótese proposta nesta pesquisa, uma vez que se observou que sempre, ao se iniciar um quadriênio, existe um aumento expressivo da produção feita pelos pesquisadores

É importante ressaltar a necessidade de intensificar a discussão em relação ao produtivismo acadêmico na área de Administração, estendendo esse problema de pesquisa a outros programas e áreas, para verificar se essas mesmas práticas de influência social ocorrem em campos da ciência.

O baixo número de entrevistados durante a pesquisa foi um resultado da resistência dos pesquisadores em dialogar sobre um tema que é visto como polêmico dentro da área de pesquisa; não só da área de Administração, mas também de outras áreas. Foram convidados 10 pesquisadores, contudo, somente 3 aceitaram o convite de realizar a pesquisa. Sobretudo por se tratar de um tema que também ocasiona muitos problemas de percalço na vida do pesquisador, pois acaba desencadeando em doenças, como infarto, acidente vascular cerebral (AVC), síndrome de Burnout, entre outros. Nesse sentido, ainda reflete uma busca desenfreada em conseguir boas parcerias com o objetivo de obter continuidade no número de suas publicações.

Por fim, para futuras pesquisas, recomendo que seja analisado como a influência social exercida sobre um determinado orientando pode estimular o volume de produção científica feita durante um determinado período e se a idade do pesquisador influencia na produção intelectual. Além disso, o escopo de futuras pesquisas pode ser ampliado para programas que possuem notas menores, visto que a produção com os dados obtidos com a pesquisa, que trata sobre a média de produção científica por programa, aumenta o volume de produção científica feita individualmente, visando identificar se esse é um fenômeno atrelado à pontuação que o programa possui pela avaliação CAPES, ou se esse fenômeno está atrelado a região em que está situado o programa.

\section{REFERÊNCIAS}

ABRAMO, G.; D’ANGELO, C. A.; COSTA, F. Research productivity: are higher academic ranks more productive than lower ones? Scientometrics, v. 88, n. 3, p. 915-928, 18 jun. 2011. DOI: $10.1007 / \mathrm{s} 11192-011-0426-6$.

ALCADIPANI, R. Resistir ao produtivismo: uma ode à perturbação acadêmica. Cadernos EBAPE BR, v. 9, n. 4, p. 1174-1178, 2011.

ALVESSON, M. Do we have something to say? From re-search to roi-search and back again. Organization, v. 20, n. 1, p. 79-90, 2013. DOI: 10.1177/1350508412460996. 
BARDIN, L. Análise de conteúdo, Tradução de Luis Antero Neto e Augusto Pinheiro. São Paulo: Martin Fontes, 1977.

BERTERO, C. O.; ALCADIPANI, R.; CABRAL, S.; FARIA, A.; ROSSONI, L. Os desafios da produção de conhecimento em Administração no Brasil. Cadernos EBAPE.BR, v. 11, n. 1, p. 181 a 196, 27 mar. 2013. DOI: 10.1590/S1679-39512013000100012.

BIANCHETTI, L.; VALLE, I. R. Produtivismo acadêmico e decorrências às condições de vida/trabalho de pesquisadores brasileiros e europeus. Ensaio: aval.pol.públ.Educ., Rio de Janeiro , v. 22, n. 82, p. 89-110, Mar. 2014. DOI: 10.1590/S0104-40362014000100005.

BLANCHFLOWER, Tiffy Machado. Research Design: quantitative, qualitative, mixed methods, arts-based, and community-based participatory research approaches. The Guilford Press, New York (NY), v. 47, n. 1, p. 101-102, set. 2018. DOI: 10.1111/fcsr.12276.

BRASIL. Parecer n 977/1965. Definição dos cursos de pós-graduação. Disponível em: $<$ https://www.capes.gov.br/images/stories/download/avaliacao/avaliacao-n/Parecer-9771965.pdf>. Acesso em: 09 nov. 2020.

BURT, R. S. Structural holes versus network closure as social capital. In: Social capital. Routledge, p. 31-56, 2017.

CAPES.2016. Documentos de área - Avaliação quadrienal CAPES. Disponível em:< http://avaliacaoquadrienal.capes.gov.br/documentos-de-area>. Acesso em 17 set. 2019.

COLEMAN, J. S. Social capital in the creation of human capital. American Journal of Sociology, v. 94, p. S95-S120, 1988.

DENZIN, N. K.; LINCOLN, Y. S. The Sage Handbook of Qualitative Research. 5 ed. Los Angeles: Sage publications, 2017.

DUCTOR, L. Does co-authorship lead to higher academic productivity? Oxford Bulletin of Economics and Statistics, v. 77, n. 3, p. 385-407, 2015. DOI: 10.1111/obes.12070.

FLEMING, L.; MINGO, S.; CHEN, D. Collaborative brokerage, generative creativity, and creative success. Administrative Science Quarterly, v. 52, n. 3, p. 443-475, 2007. DOI: 10.2189/asqu.52.3.443.

FOSTER, J. G.; RZHETSKY, A.; EVANS, J. A. Tradition and innovation in scientists' research strategies. American Sociological Review, v. 80, n. 5, p. 875-908, 2015. DOI: 10.1177/0003122415601618.

FREITAS, H.; OLIVEIRA, M.; SACCOL, A. Z.; MOSCAROLA, J. O método de pesquisa survey. RAUSP Management Journal, v. 35, n. 3, p. 105-112, 2000.

FRIEDKIN, N. E. A structural theory of social influence. Cambridge University Press, 1998.

FRIEDKIN, N. E. Structural cohesion and equivalence explanations of social homogeneity. Sociological Methods \& Research, v. 12, n. 3, p. 235-261, 1984. 
FRIEDKIN, N. E; JOHNSEN, E. C. Attitude change, affect control, and expectation states in the formation of influence networks. In: Power and Status. Emerald Group Publishing Limited, 2003. p. 1-29.

GATTI, B.; ANDRÉ, M.; FÁVERO, O.; CANDAU, V. M. F. O modelo de avaliação da CAPES. Revista Brasileira de Educação, Rio de Janeiro, n. 22, p. 137-144, abr. 2003. DOI: 10.1590/S1413-24782003000100012.

GONZALEZ-BRAMBILA, C. N.; VELOSO, F. M.; KRACKHARDT, D. The impact of network embeddedness on research output. Research Policy, v. 42, n. 9, p. 1555-1567, 2013. DOI: $\underline{10.1016 / j . r e s p o l .2013 .07 .008 . ~}$

GRANOVETTER, M. Problems of explanation in economic sociology. Networks and organizations: Structure, form, and action, p. 25-56, 1992.

GULATI, R. Social structure and alliance formation patterns: A longitudinal analysis. Administrative Science Quarterly, p. 619-652, 1995.

HE, Z-L.; GENG, X.-S.; CAMPBELL-HUNT, C. Research collaboration and research output: a longitudinal study of 65 biomedical scientists in a New Zealand university. Research Policy, v. 38, n. 2, p. 306-317, 2009. DOI: 10.1016/j.respol.2008.11.011.

HEWSTONE, M. Consequences of diversity for social cohesion and prejudice: The missing dimension of intergroup contact. Journal of Social Issues, v. 71, n. 2, p. 417-438, 2015. DOI: $\underline{10.1111 / \text { josi.12120. }}$

HORTA, H.; SANTOS, J. M. The impact of publishing during PhD studies on career research publication, visibility, and collaborations. Research in Higher Education, v. 57, n. 1, p. 2850, 2016. DOI: $10.1007 / \mathrm{s} 11162-015-9380-0$.

IMASATO, T.; PERLIN, M. S.; BORENSTEIN, D. Análise do Perfil dos Acadêmicos e de suas Publicações Científicas em Administração. Revista de Administração Contemporânea, Curitiba, v. 21, n. 1, p. 62-83, fev. 2017. DOI: 10.1590/1982$\underline{7849 \mathrm{rac} 2017150329 .}$

INKPEN, A. C.; TSANG, E. WK. Social capital, networks, and knowledge transfer. Academy of Management Review, v. 30, n. 1, p. 146-165, 2005. DOI: 10.2307/20159100.

KUHN, T. S.; EPSTEIN, J. The essential tension. American Journal of Physics, v.47, n.6, p. 568-569, jun. 1979.

LARSON, A. Network dyads in entrepreneurial settings: A study of the governance of exchange relationships. Administrative Science Quarterly, v. 37, n. 1, 1992.

LEITE, R. F. A perspectiva da análise de conteúdo na pesquisa qualitativa: algumas considerações. Revista Pesquisa Qualitativa, v. 5, n. 9, p. 539-551, 2017.

MCNUTT, M. K.; BRADFORD, M.; DRAZEN, J. M.; HANSON, B.; HOWARD, B.; JAMIESON, K. H.; KIERMER, V.; MARCUS, E.; POPE, B. K.; SCHEKMAN, R. 
Transparency in authors' contributions and responsibilities to promote integrity in scientific publication. Proceedings of The National Academy of Sciences, v. 115, n. 11, p. 2557 2560, 27 fev. 2018. DOI: 10.1073/pnas.1715374115.

MELLO, C. M.; CRUBELLATE, J. M.; ROSSONI, L. Redes de coautorias entre docentes de programas brasileiros de pós-graduação (Stricto Sensu) em Administração: aspectos estruturais e dinâmica de relacionamento. RAM. Revista de Administração Mackenzie, v. 10, n. 5, p. 130-153, out. 2009. DOI: 10.1590/s1678-69712009000500007.

MOODY, J.; WHITE, D. R. Structural Cohesion and Embeddedness: a hierarchical concept of social groups. American Sociological Review, v. 68, n. 1, p. 103, fev. 2003. DOI: $10.2307 / 3088904$.

O'REILLY, C. A.; ROBERTS, K. H. Task group structure, communication, and effectiveness in three organizations. Journal Of Applied Psychology, v. 62, n. 6, p. 674-681, 1977. DOI: $\underline{10.1037 / 0021-9010.62 .6 .674 .}$

PATRUS, R.; DANTAS, D. C.; SHIGAKI, H. B. O produtivismo acadêmico e seus impactos na pós-graduação stricto sensu: uma ameaça à solidariedade entre pares? Cadernos EBAPE.BR, v. 13, n. 1, p. 1 a 18, 7 jan. 2015. DOI: 10.1590/1679-39518866.

PHELPS, C.; HEIDL, R.; WADHWA, A. Knowledge, networks, and knowledge networks: a review and research agenda. Journal of Management, v. 38, n. 4, p. 1115-1166, 2012. DOI: $10.1177 / 0149206311432640$.

POLANYI, K.; MACIVER, R. M. The great transformation. Boston: Beacon Press, 1944.

REAGANS, R.; MCEVILY, B. Network structure and knowledge transfer: The effects of cohesion and range. Administrative Science Quarterly, v. 48, n. 2, p. 240-267, 2003. DOI: $10.2307 / 3556658$.

REGO, T. C. Produtivismo, pesquisa e comunicação científica: entre o veneno e o remédio. Educação e Pesquisa, v. 40, n. 2, 2014. DOI: 10.1590/S1517-97022014061843.

RICCI, R. G. M. S. A peculiar produção intelectual do Brasil recente. Revista Espaço Acadêmico, v. 9, n. 100, p. 16-22, 2009. DOI: 10.1590/S1415-65552009000500006.

SCIMAGO. Scimago Journal \& Country Rank. 2018. Disponível em: <https://www.scimagojr.com/countryrank.php?region=Latin\%20America >. Acesso em: 17 set. 2020.

SCOTT, J. Social network analysis: a handbook. Sage London. 2nd edition. 2000.

SERRAT, O. Social network analysis. In: Knowledge solutions. Springer, Singapore, p.3943, 2017.

SGUISSARDI, V. Produtivismo acadêmico. In: OLIVEIRA, D. A.; DUARTE, A. M. C.; VIEIRA, L. M. F. (Orgs.). Dicionário de Trabalho, Profissão e Condição Docente. Belo Horizonte: UFMG, 2010. 
SHIGAKI, H. B.; PATRUS, R. O papel da produção intelectual no sistema de avaliação dos programas de Administração pela Capes. TPA-Teoria e Prática em Administração, v. 2, n. 2, p. 126-150, 2013. DOI: 10.21714/2238-104X2012v2i2-14015

SHIGAKI, H. B.; PATRUS, R. Revisão por pares e produtivismo acadêmico sob a ótica de avaliadores de artigos de periódicos em Administração. RBPG. Revista Brasileira de PósGraduação, v. 13, n. 31, 2016. DOI: 10.21713/2358-2332.2016.v13.960

SOUZA, Q.; QUANDT, C. Metodologia de análise de redes sociais. In: DUARTE, F.; QUANDT, C.; SOUZA, Q (orgs). O tempo das redes. São Paulo: Perspectiva, 2008.

STRANG, D.; FRIEDKIN, N. E. A Structural Theory of Social Influence. Administrative Science Quarterly, v. 45, n. 1, p. 162-164, mar. 2000.

TORRISI, B. Academic productivity correlated with well-being at work. Scientometrics, v. 94, n. 2, p. 801-815, 2013. DOI: $10.1007 / \mathrm{s} 11192-012-0709-6$

WASSERMAN, S.; FAUST, K. Social network analysis: methods and applications. Cambridge university press, 1994.

ZUCKERMAN, H. Nobel laureates in science: Patterns of productivity, collaboration, and authorship. American Sociological Review, p. 391-403, 1967. 